\title{
Maternal and Perinatal Complications of Severe Preeclampsia in Three Referral Hospitals in Yaoundé, Cameroon
}

\author{
Jean Dupont Kemfang Ngowa ${ }^{1,2 *}$, Jean Marie Kasia ${ }^{1,2}$, Jean Alima ${ }^{2}$, Joel Fokom Domgue², \\ Anny Ngassam ${ }^{2}$, Jean Baptiste Bogne ${ }^{3}$, Sebastien Mba $^{4}$ \\ ${ }^{1}$ Obstetrics and Gynecology Unit, Yaoundé General Hospital, Yaoundé, Cameroon \\ ${ }^{2}$ Department of Obstetrics and Gynecology, Faculty of Medicine and Biomedical Sciences, University of \\ Yaoundé I, Yaoundé, Cameroon \\ ${ }^{3}$ Department of Pediatrics, Faculty of Medicine and Biomedical Sciences, University of Yaoundé I, Yaoundé, \\ Cameroon \\ ${ }^{4}$ Anesthesia and Intensive Care Unit, Yaoundé General Hospital, Yaoundé, Cameroon \\ Email: *jdkemfang@yahoo.fr
}

Received 17 September 2015; accepted 25 October 2015; published 28 October 2015

Copyright (C) 2015 by authors and Scientific Research Publishing Inc.

This work is licensed under the Creative Commons Attribution International License (CC BY).

http://creativecommons.org/licenses/by/4.0/

(c) (i) Open Access

\section{Abstract}

Objective: The aim of this study was to determine maternal and perinatal complications of pregnancies complicated by severe preeclampsia in three tertiary care centers in Cameroon. Methods: We carried out a descriptive cross sectional study from the $1^{\text {st }}$ of June 2012 to the $31^{\text {th }}$ of June 2014, among pregnant women with severe preeclampsia followed up in three tertiary level hospitals in Yaoundé, Cameroon: the Yaoundé General Hospital, the Yaoundé Central Hospital, and the Yaoundé University Hospital. Statistical analysis was performed using EPI 3.5.5. Data were described as means \pm standard deviation, percentages and numbers. Chi-square and Fisher exact tests were used where appropriate. Results: Of the $\mathbf{2 5 0 0}$ deliveries registered during the study period, 111 cases (8.49\%) were managed as severe preeclampsia. Four patients refused to participate and were excluded from the study. Most of these patients were non workers $(58.0 \%)$, pauciparous $(61.7 \%)$ and young (median age of 27.47 years \pm 6.46$)$. Eclampsia $(12.14 \%)$, abruptio placentae $(11.21 \%)$ and hypertensive retinopathy $(7.47 \%)$ were the most frequent maternal complications. Two cases $(1.86 \%)$ of maternal deaths occurred in patients who had eclampsia. Prematurity $(48.6 \%)$, intra uterine fetal death $(13.1 \%)$ and oligoamnios $(11.2 \%)$ were the most frequent fetal complications. All four neonatal deaths occurred in women in whom the diagnosis of severe preeclampsia was done between 28 and 33 weeks of gestation. Conclusion: Pregnancies complicated by severe preeclampsia had significantly high maternal and perinatal morbidity and mortality in Cameroon. The complications of severe preeclampsia can be prevented by more widespread

${ }^{*}$ Corresponding author. 
use of antenatal care, education of primary medical care personnel, prompt diagnosis of high-risk patients and timely referral to tertiary medical centers.

\section{Keywords}

Pregnancy, Hypertension, Severe Preeclampsia, Maternal and Perinatal Complications, Cameroon

\section{Introduction}

Hypertensive disorders of pregnancy (HDP) are a major cause of maternal morbidity and mortality and lead to about $10 \%-15 \%$ of maternal deaths worldwide especially in developing countries [1]. Severe forms of HDP include preeclampsia and eclampsia, which are the leading causes of maternal death in many parts of the world [2].

About $30 \%$ of HDP are associated with chronic hypertension while $70 \%$ of cases occur in pregnant women without a history of hypertension [3]. Preeclampsia is a multisystem disorder of unknown etiology, unique to pregnancy [4]-[6]. While preeclampsia complicates $6 \%-10 \%$ of all pregnancies in the United States, the incidence is believed to be even higher in underdeveloped countries [7]. In Cameroon, preeclampsia occurs in $4.9 \%$ to $7.7 \%$ of pregnancies [8].

Preeclampsia is characterized as mild or severe based on the degree of hypertension, proteinuria, the presence of symptoms resulting from involvement of the kidneys, brain, liver, and cardiovascular system [9]. Abruptio placenta, acute renal failure (ARF), cerebral hemorrhage, disseminated intravascular coagulation (DIC), hepatic failure, and circulatory collapse are consequences of severe preeclampsia/eclampsia and may be lethal to patients [10]. Intrauterine fetal growth restriction (IUGR), intrauterine fetal death (IUFD) and prematurity appear to be the other related obstetric problems associated with severe preeclampsia [11].

All these clinical conditions mandate prompt diagnosis and rapid management in order to improve maternal and perinatal outcomes which are sometimes suboptimal in developing countries. The purpose of this study was to determine maternal and fetal complications of pregnancies complicated by severe preeclampsia in three referral hospitals in Yaoundé, the capital city of Cameroon.

\section{Methods}

We carried out a descriptive cross-sectional study from $1^{\text {st }}$ June 2012 to $31^{\text {th }}$ June 2014 among pregnant women with severe preeclampsia follow-up in three tertiary level hospitals in Yaoundé, Cameroon: the Yaoundé General Hospital, the Yaoundé Central Hospital, and the Yaoundé University Hospital.

These hospitals receive pregnant women from all parts of the country, most of whom are people from Yaoundé. The health personnel of the maternity units of these hospitals include obstetricians/gynecologists, residents and midwives. In these hospitals, cases of high-risk pregnancies are managed of by obstetricians or residents in obstetrics under the supervision of an obstetrician.

In these hospitals, management of patients with severe preeclampsia include hospitalization, bed rest, antihypertensive drugs (Nicardipine or Nifedipine), administration of Magnesium Sulphate to prevent eclampsia (4 g intramuscular into each buttock and $4 \mathrm{~g}$ intravenous loading dose followed by the maintenance dose of $4 \mathrm{~g}$ intramuscular every 4 hours); ringer lactate solution infusion at the rate of $60 \mathrm{ml} /$ hour, for plasma volume expansion and a close materno-fetal monitoring. Termination of pregnancy is achieved immediately if the gestational age is 34 completed weeks or more. However for pregnancies under 34 weeks, the decision to terminate the pregnancy can be delayed and is often discussed on a case by case basis with neonatologists. Administration of corticosteroid (Betamethasone at a dose of $12 \mathrm{mg}$ intramuscular to be repeated after 24 hours or Dexamethasone at $6 \mathrm{mg}$ intramuscular to be repeated three times every 12 hours) to accelerate fetal lung maturation was systematic for these pregnancies under 34 weeks.

In Cameroon, the diagnosis of hypertension in pregnancy is based on the criteria defined by the National High Blood Pressure Education Programme Working Group on High Blood Pressure in Pregnancy [11]. Severe preeclampsia was defined by the presence of one or more of the following criteria: blood pressure $\geq 160 / 110 \mathrm{mmHg}$, proteinuria $\geq 3.5 \mathrm{~g} / 24 \mathrm{~h}$, oliguria $(<600 \mathrm{ml} / 24 \mathrm{~h})$, IUGR $\left(<10^{\text {th }}\right.$ percentile $)$, oligoamnios; symptoms suggesting end organ failure such as headache, visual disturbances, epigastric pain; medical complications including pul- 
monary edema, cerebral edema, acute renal failure, hepatic hematoma, HELLP syndrome (hemolysis, elevated liver enzymes and low platelets count). The occurrence of convulsions not attributable to other conditions in a patient with preeclampsia was considered as eclampsia. We recorded data regarding demographic parameters, gestational age (determined by last menstrual period when known or first trimester obstetrical ultrasound), medical conditions such as hypertension, diabetes mellitus, history of smoking, presenting signs and symptoms, blood pressure on admission, laboratory evaluation on admission (full blood count, liver enzymes, urea, creatinine, uric acid, coagulation profile) and 24 hours proteinuria.

Obstetrical complications including preterm delivery and abruptio placentae; materno-fetal complications including maternal deaths, perinatal deaths, low birth weight ( $<2500$ grams), low Apgar score $\left(<7\right.$ at $5^{\text {th }}$ minute) were also gathered from the available data on medical recording files. Perinatal mortality rate was defined as the number of all fetal (at 28 weeks of gestation and above) and neonatal (during the first 7 days after birth) deaths/ 1000 live births.

Statistical analysis was performed using EPI 3.5.5. Data was defined as means \pm standard deviation, percentages and numbers. Chi-square and Fisher exact test were used where appropriate. $\mathrm{P}$ value $<0.05$ was considered to be statistically significant.

\section{Results}

During the study period, 2500 deliveries occurred in the selected hospitals and 111 (4.44\%) were complicated by severe preeclampsia. Four patients refused to participate and were excluded from the analysis. The remaining 107 women formed the study population. The patients' age ranged from 16 to 45 years with a mean of $27.47 \pm$ 6.46 years.

Table 1 shows the sociodemographic characteristics of the study population. About half (49.5\%) of patients had secondary education level, about two-thirds (64.5\%) were single and $58 \%$ were non workers (housewives or students).

Table 2 shows the clinical characteristics of the study population. Primiparous women were the most represented $(43.92 \%)$. However, a history of preeclampsia was found in $14.95 \%$ of patients with severe preeclampsia and a history of chronic hypertension in $10.89 \%$ of women. Severe proteinuria $(100 \%)$, high blood pressure $(92 \%)$ and neurological symptoms such as severe headache, visual disturbances $(62 \%)$, were the most frequent

Table 1. Sociodemographic characteristics of the study population; $N=107$.

\begin{tabular}{lcc}
\hline \multicolumn{1}{c}{ Variables } & $\mathrm{n}$ & $\%$ \\
\hline Age range (years) & 18 & 16.9 \\
$16-20$ & 56 & 52.3 \\
$21-30$ & 30 & 28 \\
$31-40$ & 3 & 2.8 \\
$>40$ & & \\
Educational level & 14 & 13.08 \\
Primary & 53 & 49.5 \\
Secondary & 40 & 37.4 \\
University & & \\
Profession & 25 & 23.4 \\
House wife & 37 & 34.57 \\
Student & 45 & 42.05 \\
Salaried employee & & 35.5 \\
Marital status & 38 & 64.48 \\
Married & 69 & \\
Single & & \\
\hline
\end{tabular}


Table 2. Clinical characteristics of study population; $\mathrm{N}=107$.

\begin{tabular}{|c|c|c|}
\hline Clinical characteristics & $\mathbf{n}$ & $\%$ \\
\hline \multicolumn{3}{|l|}{ Parity } \\
\hline Nulliparous & 18 & 16.82 \\
\hline Primiparous & 47 & 43.92 \\
\hline Multiparous & 42 & 39.25 \\
\hline \multicolumn{3}{|l|}{ History of hypertension } \\
\hline Personal history of pre-eclampsia & 16 & 14.95 \\
\hline Personal history of chronic hypertension & 11 & 10.29 \\
\hline Normalized blood pressure under treatment & 54 & 50.46 \\
\hline \multicolumn{3}{|l|}{ Signs of severe preeclampsia at diagnosis } \\
\hline $\mathrm{BP}>160 / 110 \mathrm{mmHg}$ & 99 & 92.52 \\
\hline Neurological symptoms & 66 & 61.68 \\
\hline Severe IUGR or oligoamnios & 16 & 14.95 \\
\hline Low platelets count $<100,000 / \mathrm{ml}$ & 8 & 07.47 \\
\hline Proteinuria $>3.5 \mathrm{~g} / 24 \mathrm{~h}$ & 107 & 100 \\
\hline Liver enzymes above three times the normal values & 2 & 01.86 \\
\hline \multicolumn{3}{|l|}{ Period of diagnosis of severe preeclampsia } \\
\hline Ante partum & 54 & 50.46 \\
\hline Per partum & 48 & 44.85 \\
\hline Post-partum & 5 & 04.67 \\
\hline \multicolumn{3}{|l|}{ Gestational age at diagnosis } \\
\hline $28-33$ weeks & 40 & 37.4 \\
\hline 34 - 36 weeks & 12 & 11.2 \\
\hline$\geq 37$ weeks & 55 & 51.4 \\
\hline \multicolumn{3}{|l|}{ Mode of delivery } \\
\hline Vaginal & 62 & 57.94 \\
\hline Cesarean section & 45 & 42.6 \\
\hline \multicolumn{3}{|l|}{ Time interval from diagnosis to delivery, $\mathrm{n}=102$} \\
\hline$<24 \mathrm{~h}$ & 77 & $\mathbf{7 5 . 4 0}$ \\
\hline$>24 \mathrm{~h}$ & 25 & 24.50 \\
\hline
\end{tabular}

IUGR: intra uterine growth retardation; BP: Blood Pressure.

signs of severe preeclampsia in our study population. Severe preeclampsia was diagnosed at term in about half $(51 \%)$ of women. The cesarean section rate in the study population was $42.6 \%$ and $75 \%$ of women had delivered within 24 hours following the diagnosis of severe preeclampsia, cesarean section rate was $75 \%$. For cases of severe preeclampsia diagnosed before 34 weeks of gestation, the average time interval between diagnosis and delivery was 4.67 days $+/-4.5$, for those who were diagnosed between 28 and 32 weeks of gestation and 3.58 days \pm 1.5 , for those diagnosed between 33 and 34 weeks of gestation. After 34 weeks of gestation, this time interval was within one day.

Table 3 shows maternal complications of severe preeclampsia. Eclampsia (12.14\%); abruptio placenta (11.21\%) and hypertensive retinopathy $(7.47 \%)$ were the most frequent maternal complications. We recorded two cases of 
Table 3. Maternal complications of severe preeclampsia in the study population.

\begin{tabular}{lcc}
\hline \multicolumn{1}{c}{ Maternal complications } & n & \% \\
\hline Eclampsia & 13 & 12.14 \\
Hypertensive retinopathy & 8 & 7.47 \\
CVA & 3 & 2.80 \\
HELLP syndrome & 2 & 1.86 \\
Acute renal failure & 2 & 1.86 \\
Abruptio placenta & 12 & 11.21 \\
DIC & 1 & 0.93 \\
Post-partum hemorrhage & 7 & 6.54 \\
Severe anemia & 6 & 5.60 \\
Severe ascitis & 1 & 0.90 \\
Maternal death & 2 & 1.86 \\
\hline
\end{tabular}

CVA: cerebral vascular accident; HELLP: DIC: disseminated intravascular coagulation.

maternal deaths that occurred in patients who had eclampsia.

Concerning perinatal complications of severe preeclampsia, preterm delivery complicated $48.6 \%$ of pregnancies in the study population. The mean birth weight was 2454.07 grams \pm 881 and $46.72 \%$ of newborns presented a low birth weight (birth weight $<2.500$ grams).

Table 4 shows perinatal complications with respect to gestational age, among women with severe preeclampsia in the study population. IUFD and oligoamnios were the most frequent fetal complications. In addition, oligoamnios rate was statistically more frequent in 28 - 33 weeks gestational age group than in $\geq 34$ weeks gestational age group. All four neonatal deaths occurred in the $28-33$ weeks gestational age group.

\section{Discussion}

We examined maternal and perinatal outcomes for severe preeclampsia and eclampsia in three reference hospitals of Yaoundé, the capital city of Cameroon. We found that: 1) The median gestational age at diagnosis was 37 weeks of gestation. 2) The cesarean section rates were $42.6 \%$ and $75 \%$ respectively for general study population and for women had delivered within 24 hours following the diagnosis of severe preeclampsia. 3) Eclampsia (12.14\%), abruptio placentae $(11.21 \%)$ and hypertensive retinopathy $(7.47 \%)$ were the most frequent maternal complications. 4) Preterm delivery, IUFD and oligoamnios were the most frequent fetal complications. 5) All maternal deaths (two) occurred in patients with eclampsia, and all neonatal deaths (four) occurred in the 28 - 33 weeks' gestational age group.

Primaparous young women with low socioeconomic status are the most typical preeclamptic cases. Our study also revealed clinical and sociodemographic data similar to the patient profiles in the extant literature [12]. Most of these patients were non workers (58.0\%), pauciparous $(61.7 \%)$ and young (median age of 27.47 years \pm 6.46 ). In addition, past history of preeclampsia was found in $14.95 \%$ of patients and personal history of chronic hypertension in $10.89 \%$ of women with severe preeclampsia. Therefore, community health education should be reinforced to improve awareness of our population about the risk factors for HDP and especially preeclampsia.

Pregnancies complicated by severe preeclampsia are associated with an increased risk for maternal morbidity and mortality. Complications leading to maternal morbidity include severe bleeding from abruptio placenta, HELLP syndrome, pulmonary edema, ARF, cerebrovascular hemorrhage, and liver rupture. These complications are usually seen in women who develop severe preeclampsia before 32 weeks gestation [13]. In this study, we found that eclampsia (12.14\%); abruptio placenta (11.21\%) and hypertensive retinopathy $(7.47 \%)$ were the most frequent maternal complications. This is in line with a previous study carried out in Cameroon by Mboudou et al., which reported abruptio placenta and eclampsia among the most common complication of preeclampsia [8]. All cases of maternal deaths occurred in patients with eclampsia, which is also consistent with the study by Mboudou et al. [8]. Irregular or absent antenatal visits, late admission to medical facilities and improper 
Table 4. Perinatal complications with respect to gestational age among women with severe preeclampsia.

\begin{tabular}{|c|c|c|c|c|c|c|c|}
\hline \multirow{3}{*}{ Perinatal complications } & \multicolumn{6}{|c|}{ Gestational age } & \multirow{3}{*}{$\mathbf{P}$} \\
\hline & \multicolumn{2}{|c|}{$\geq 28$ weeks $(N=107)$} & \multicolumn{2}{|c|}{$28-33$ weeks $(n=40)$} & \multicolumn{2}{|c|}{$\geq 34$ weeks $(n=67)$} & \\
\hline & $\mathbf{n}$ & $\%$ & $\mathbf{n}$ & $\%$ & $\mathbf{n}$ & $\%$ & \\
\hline \multicolumn{8}{|l|}{ Fetal complications } \\
\hline IUFD & 14 & 13.0 & 8 & 20 & 6 & 08.9 & 0.179 \\
\hline IUGR & 10 & 09.3 & 9 & 22.5 & 1 & 01.4 & 0.001 \\
\hline Oligoamnios & 12 & 11.2 & 7 & 17.5 & 5 & 07.4 & 0.202 \\
\hline Acute fetal distress & 6 & 05.6 & 4 & 10 & 2 & 02.9 & 0.274 \\
\hline \multicolumn{8}{|l|}{ Neonatal complications } \\
\hline APGAR score $<7$ at $5^{\text {th }}$ minute & 24 & 22.4 & 13 & 32.5 & 11 & 16.4 & 0.090 \\
\hline Respiratory distress & 16 & 14.9 & 14 & 35 & 2 & 02.9 & 0.000 \\
\hline Neonatal infection & 13 & 12.1 & 9 & 22.5 & 4 & 03.7 & 0.0067 \\
\hline Intraventricular hemorrhage & 1 & 0.9 & 1 & 02.5 & 0 & 0 & $\mathbf{N A}$ \\
\hline Neonatal death & 4 & 03.7 & 4 & 10 & 0 & 0 & NA \\
\hline
\end{tabular}

IUFD: intra uterine fetal death; IUGR: intra uterine growth retardation; NA: non applicable.

anticonvulsive prophylaxis at primary care units, may be responsible for late diagnosis and poor outcomes. This data support the importance of early detection and adequate management of HDP to prevent complications that might be lethal to patients. Since most patients received in these tertiary level hospitals are referred from primary or secondary health facilities, efforts must focus on training midwives and other primary health care workers on screening and proper management of HDP.

Fetal complications associated with severe preeclampsia include prematurity, IUGR, oligoamnios, fetal distress and low APGAR scores at birth. Obviously, IUGR with oligoamnios and fetal distress and preterm birth of a fetus consequently carry a high-risk of early neonatal death due to complications of prematurity. The most common fetal complication of severe preeclampsia in our study was prematurity, which is consistent with the findings by Mboudou et al. [8]. Indeed, severe preeclampsia manifests on average between 32 and 34 weeks of gestation. It is common clinical practice that a 32 - 34 weeks pregnancy complicated by severe preeclampsia should be delivered immediately. In this study, the time interval between diagnosis of severe preeclampsia and termination of pregnancy was on average 3.58 days \pm 1.5 between 32 and 34 weeks of gestation. This delay could be explained by the need for obstetricians to stabilize the clinical conditions of the patient before delivery and administration of corticosteroids for fetal lung maturation [14].

In our study, four neonatal deaths were recorded and all occurred between 28 and 33 weeks of gestation. This supports the hypothesis that neonatal death following HDP is usually due to premature delivery. It is generally accepted that perinatal and neonatal morbidity and mortality rates increase in pregnancies complicated by severe preeclampsia or eclampsia. Different perinatal morbidity and mortality rates are presented in literature [15]-[16].

Operative delivery is reported to be increased in hypertensive disorders in pregnancy [17]. Vaginal delivery is recommended in patients with severe preeclampsia in the absence of obstetric indication for cesarean section. Elective abdominal delivery may be preferred in cases before 30 weeks of gestation with poor Bishop score or cases before 32 weeks with IUGR and oligoamnios [18]. Coppage et al. concluded that immediate abdominal delivery did not improve maternal and neonatal outcomes in patients with severe preeclampsia and induction of vaginal delivery did not lead to increased morbidity and mortality [19]. In our study, the rate of cesarean section was as high as $42.6 \%$. This can be explained by the fact that health facilities where the study was carried out are referral hospitals and most patients arrived with obstetrics complications that might have prompted obstetricians to perform cesarean section.

\section{Conclusion}

This study demonstrates that pregnancies complicated by severe preeclampsia have significantly high maternal 
and perinatal morbidity and mortality in our setting. The devastating effects of hypertensive disorders in pregnancy could be prevented by close antenatal follow-up and reasonable management strategies. Early detection of high-risk individuals and mild cases by well-trained medical professionals in primary health centers and timely referral to advanced tertiary centers will lead to improved perinatal and maternal outcomes in this critical group of patients.

\section{References}

[1] Roberts, J.M., Pearson, G., Cutler, J. and Lindheimer, M. (2003) Summary of the NHLBI Working Group on Research on Hypertension during Pregnancy. Hypertension, 41, 437-445. http://dx.doi.org/10.1161/01.HYP.0000054981.03589.E9

[2] Villar, J., Say, L., Gulmezoglu, A.M., Marialdi, M., Lindheimer, M.D., Betran, A.P., et al. (2003) Pre-Eclampsia Eclampsia: A Health Problem for 2000 Years. In: Critchly, H., MacLean, A., Poston, L. and Walker, J., Eds., Preeclampsia, RCOG Press, London, 189-207.

[3] Bergström, S., Povey, G., Songane, F. and Ching, C. (1992) Seasonal Incidence of Eclampsia, Its Relationship to Meteorological Data in Mozambique. Journal of Perinatal Medicine, 20, 153-158.

[4] Odendaal, H.J., Pattinson, R.C., Bam, R., Grove, D. and Kotze, T.J. (1990) Aggressive or Expectant Management for Patients with Severe Preeclampsia between 28 and 34 Weeks' Gestation: A Randomized Controlled Trial. Obstetric and Gynecologic, 76, 1070-1075.

[5] Sibai, B.M., Akl, S., Fairlie, F. and Moretti, M. (1990) A Protocol for Managing Severe Preeclampsia in the Second Trimester. American Journal of Obstetric and Gynecologic, 163, 733-738. http://dx.doi.org/10.1016/0002-9378(90)91058-K

[6] Chua, S. and Redman, C.W. (1992) Prognosis for Preeclampsia Complicated by 5 g or More of Proteinuria in 24 Hours. The European Journal of Obstetrics \& Gynecology and Reproductive Biology, 43, 9-12. DOI: 10.1016/0028-2243(92) 90236-R

[7] Oláh, K.S., Redman, C.W. and Gee, H. (1993) Management of Severe, Early Preeclampsia: Is Conservative Management Justified? The European Journal of Obstetrics \& Gynecology and Reproductive Biology, 51, 175-180. http://dx.doi.org/10.1016/0028-2243(93)90032-8

[8] Mboudou, E.T., Foumane, P., Belley, Priso, E., Dohbit, J., Ze, Minkande, J., Nkengafac, W.M. and Doh, A.S. (2009) Hypertension au cours de la grossesse: Aspects cliniques et épidémiologiques à l'Hôpital Gynéco-Obstétrique et Pédiatrique de Yaoundé, Cameroun. Clinics in Mother and Child Health, 6, 1087-1093.

[9] Yalcin, O.T., Sener, T., Hassa, H., Ozalp, S. and Okur, A. (1998) Effects of Postpartum Corticosteroids in Patients with HELLP Syndrome. International Journal of Gynecology \& Obstetrics, 61, 141-148. http://dx.doi.org/10.1016/S0020-7292(98)00036-8

[10] ACOG Technical Bulletin. Hypertension in Pregnancy. Number 219--January 1996 (Replaces No. 91, February 1986). Committee on Technical Bulletins of the American College of Obstetricians and Gynecologists. International Journal of Gynecology \& Obstetrics, 53, 175-183.

[11] National High Blood Pressure Education Program Working Group (2000) Report of the National High Blood Pressure Education Program Working Group on High Blood Pressure in Pregnancy. American Journal of Obstetrics and Gynecology, 183, S1-S22. http://dx.doi.org/10.1067/mob.2000.107928

[12] Yıldırım, G., Güngördük, K., Aslan, H., Gül, A., Bayraktar, M. and Ceylan, Y. (2011) Comparison of Perinatal and Maternal Outcomes of Severe Preeclampsia, Eclampsia, and HELLP Syndrome. Journal of the Turkish German Gynecological Association, 12, 90-96. http://dx.doi.org/10.5152/jtgga.2011.22

[13] Levine, R.J., Hauth, J.C., Curet, L.B., Sibai, B.M., Catalano, P.M., Morris, C.D., et al. (1997) Trial of Calcium to Prevent Preeclampsia. The New England Journal of Medicine, 337, 69-76. http://dx.doi.org/10.1056/NEJM199707103370201

[14] Kuschel, B., Zimmermann, A., Schneider, K.T.M. and Fischer, T. (2004) Prolongation of Pregnancy Following Eclampsia. European Journal of Obstetrics and Gynecology, 113, 245-247. http://dx.doi.org/10.1016/j.ejogrb.2003.06.005

[15] Yücesoy, G., Özkan, S., Bodur, H., Tan, T., Çalışkan, E., Vural, B., et al. (2005) Maternal and Perinatal Outcome in Pregnancies Complicated with Hypertensive Disorder of Pregnancy: A Seven-Year Experience of a Tertiary Care Center. Archives of Gynecology and Obstetrics, 273, 43-49. http://dx.doi.org/10.1007/s00404-005-0741-3

[16] Gul, A., Cebeci, A., Aslan, H., Polat, I., Ozdemir, A. and Ceylan, Y. (2005) Perinatal Outcomes in Severe Preeclampsia-Eclampsia with and without HELLP Syndrome. Gynecologic and Obstetric Investigation, 59, 113-118. http://dx.doi.org/10.1159/000082648 
[17] Gofton, E.N., Capewell, V., Natale, R. and Gratton, R.J. (2001) Obstetrical Intervention Rates and Maternal and Neonatal Outcomes of Women with Gestational Hypertension. American Journal of Obstetrics and Gynecology, 185, 798803. http://dx.doi.org/10.1067/mob.2001.117314

[18] Sibai, B.M. (1996) Hypertension in Pregnancy. In: Gabbe, S.G., Niebyl, J.R. and Simpson, J.L., Eds., Obstetrics: Normal and Problem Pregnancies, 3rd Edition, Churchill Livingston, New York, 935-996.

[19] Coppage, K.H. and Polzin, W.J. (2002) Severe Preeclampsia and Delivery Outcomes: Is Immediate Cesarean Delivery Beneficial? American Journal of Obstetrics and Gynecology, 186, 921-923. http://dx.doi.org/10.1067/mob.2002.124041 